\title{
O PAPEL DA REPÚBLICA NA INSTRUÇÃO PRIMÁRIA SEGUNDO PRIMITIVO MOACYR
}

Luiz Antonio de Oliveira1

Maria Cristina Gomes Machado2

\section{RESUMO}

O artigo apresenta a compreensão da escola pública primária nos recortes de Primitivo Moacyr (1869-1942) no período da Primeira República. As fontes principais são os livros partir das publicações "A instrução e a República" (7 volumes), "O Ensino Público no Congresso Nacional Breve Notícia" (1916) e os "A instrução pública no Estado de São Paulo." O estudo ampara-se no princípio da proposta conservadora (MONARCHA, 1989) que marcou o discurso e prática de modernização dos "homens cultos." Moacyr, ao coligir as fontes, retomou questões e fatos que indicam a existência de posturas e ideários próprios. A contemporaneidade e adesão à causa republicana não se apresenta em Primitivo Moacyr solidária à negação do passado e sua responsabilização pela situação do presente, conforme fora comum nos intelectuais e políticos republicanos de seu tempo. De outro lado, a centralidade da instrução como mecanismo de construção do reordenamento do Brasil o insere na perspectiva positivista. É o que o autor encontrará no texto organizado em quatro tópicos: Considerações gerais para a leitura de Primitivo Moacyr; Conjeturas sobre o lugar da instrução na condição republicana brasileira; O referencial de instrução republicana - observações de Primitivo Moacyr; A participação da República no fomento da instrução pública primária.

Palavras-chave: Educação Pública; História da Educação; Primitivo Moacyr; História dos Intelectuais.

\section{THE REPUBLIC'S ROLE IN EDUCATION PRIMARY ACCORDING OF PRIMITIVE MOACYR}

\begin{abstract}
The paper aims the understanding of the public elementary school in the Primitivo Moacyr (18691942 ) in the period of the First Republic. The main sources are the books from the publications "A instrução e a República" 1 (7 volumes), "O Ensino Público no Congresso Nacional - Breve Notícia" (1916) and the "A instrução pública no Estado de São Paulo". The study is sustained in the principle of conservative proposal (MONARCHA, 1989) that marked the discourse and practice of the modernization of "learned men". Moacyr, to collect sources, resumed issues and facts that indicate the existence of postures and own ideals. The contemporary and adherence to the republican cause is not presented in the Primitivo Moacyr solidarity the denial of the past and their accountability for the present situation, as it was common in the intellectual and Republican politicians of his time. On the other hand, the centrality of education as construction mechanism of the reordering of Brazil it inserts in the positivist perspective. The text is organized into four topics: General Considerations for the Primitivo Moacyr's reading; Conjectures about the place of education in Brazilian republican status; The Republican instructional reference - observations of Primitivo Moacyr; The participation of the Republic in the promotion of primary public education.
\end{abstract}

Keywords: Public Education, History of Education; Primitivo Moacyr, History of Intellectuals. 


\section{INTRODUÇÃO}

O texto estuda as contribuições de Primitivo Moacyr (1867-1942) ${ }^{3}$ quanto ao debate da instituição da escola pública primária no Brasil da Primeira República a partir das publicações "A instrução e a República"4 (7 volumes), os dois volumes de "A instrução pública no Estado de São Paulo" e "A instrução pública no Congresso Nacional. Breves notícias" (1916). Este último ${ }^{5}$ completa centenário em 2016. A publicação é uma organização de artigos publicados por Primitivo Moacyr no Jornal do Commercio nos anos anteriores. Passados 13 anos da referida publicação, o autor manifestou-se, em artigo publicado no mesmo periódico, denominando "Crônica Inatual I", de 23 de setembro de 1929, sobre a publicação de 1916, no qual afirmou que mantinha os mesmos conceitos da indiferença do poder público pela instrução expresso na rejeição das emendas dos deputados Tavares Cavalcanti e Afrânio Peixoto por ocasião das discussões da reforma constitucional de 1925. "As emendas foram retiradas, a despeito dos protestos de seus autores." (MOACYR, Chronica Inactual I, 1920).

Apesar das resistências, a revisão bibliográfica confirma a condição de referência clássica da obra de Moacyr enquanto contribuição para a historiografia da educação brasileira (STAMATTO, 1992). Trata-se de obra constantemente referenciada por autores que tratam de diversos objetos e variadas temáticas no contexto da referida produção historiográfica. Entretanto, não se confirma a condição de obra pesquisada. O que se podem identificar foram incursões em Moacyr, por conta de problemas e temas, motivados por diversos objetos da pesquisa em história da educação. Segundo Tanuri (1997), o autor é parte de uma tradição na escrita da história da educação brasileira que se tornou contribuição relevante ao produzir obras que se perpetuaram como referências obrigatórias por darem

[...] início ao trabalho de construção historiográfica e de organização de fontes, e por ter produzido algumas obras que ouso dizer, tornaram-se quase clássicas e, por isso, ainda hoje fornecem contribuição relevante e constituem referências obrigatórias, em que pese o fato de que outras leituras/representações já tenham sido feitas e ainda possam e devam ser feitas dos mesmos objetos de estudo. (TANURI, 1997, p.140).

Primitivo Moacyr trabalhou basicamente com legislação, e com o processo de seu debate. Neste sentido, é fundamental considerar como no quadro teórico interpretativo, que tal conjunto jurídico constitui-se como "[...] síntese de múltiplas determinações, porque [...] nela estão presentes utopias, sonhos, desejos, projetos políticos, interesses pessoais e de grupos, direitos e deveres dos cidadãos ou categorias profissionais, planos de carreiras, preconceitos, inclusões/exclusões, enfim, todas as contradições da sociedade. (CASTANHA, 2011, p. 326).

"Nesse sentido é que se diz que uma fonte nunca está esgotada e que a história é sempre reescrita, na medida em que depende do problema proposto a ser enfrentado [...]". (LOPES; GALVÃO, 2001, p. 92). O que dá expressão à afirmação de Afrânio Peixoto de que os pesquisadores sempre retornariam a Moacyr, mesmo quando a intenção não fosse explícita, dada a sua condição de repositório de informações e fontes, a partir das quais o autor conjecturou sua perspectiva para a solução do problema da instrução primária na realidade brasileira. Peixoto (1876-1947) prefaciou o livro com elogio à condição de pesquisador. A comparação com Varnhagem deu ao título publicado status de matéria-prima para novos estudos em educação: "No Brasil não se pesquisa. Todos tiramos de nós a substância de nossos escritos. A história nessas condições é repetição, é comentário, é fantasia interpretativa." (PEIXOTO, 1936, p.7). 
O estudo ampara-se no princípio da proposta conservadora (MONARCHA, 1989) que marcou o discurso e prática de modernização dos "homens cultos". Segundo Monarcha (1989) trata-se de uma proposta conservadora consolidada por certa historiografia que se tornou hegemônica na primeira metade do século XX. O autor reporta-se à leitura positivista da história que perspectiva-se em enredo modernista, segundo o qual a repetição dos processos e fases do progresso moderno é a condição que impetrava-se à modernização do Brasil, e, ou ao qual se deva ser decorrente ou influenciado para que se dê o processo de modernidade: repetir o que se deu nas nações industrializadas. Neste conceito, a leitura do passado e contemporaneidade por Fernando de Azevedo, entre outros, solidificou tal perspectiva. Destaque-se que Monarcha amplia compreensão da escrita positivista da história. Não se reduz a coletar, arquivar, coligir e publicar documentos, mas fundamentalmente, a silenciar o passado e contribuir com projetos de controle e remodelação da sociedade. Trata-se de historiografia que promoveu a propositura conservadora de sociedade encerrada no ideário escolanovista brasileiro enquanto tributária da regeneração dos costumes e da contenção social.

Assim, os anos 1930 são apresentados como o tempo da revolução que rompeu com a tradição, abrindo caminho para o processo de modernização. A desqualificação do passado e seu esquecimento se fez norma, marcando políticos, intelectuais, e boa parte dos escolanovistas. Na perspectiva conservadora preconizada pelos "homens cultos" dos anos 1920, entre os quais os "pioneiros da educação", a fábrica e urbanização são os espelhos da ação escolar e pedagógica como fundamento do progresso social e econômico. A educação escolar aparece como instrumento de coerção nos discursos dos intelectuais no forjamento da cultura de unidade nacional. Os intelectuais assumiam-se como responsáveis pela construção da nação, identidade nacional e das instituições necessárias para tal.

Nesta perspectiva missionária, as diversidades de concepções políticas destes intelectuais foram unificadas com o fortalecimento do Estado que ampliou as reivindicações dos segmentos dirigentes seguindo a tradicional visão hierárquica da ordem social. Desta forma, "como o ensino elementar era necessário ao funcionamento duma sociedade moderna, devia-se providenciar que ele apenas se cingisse a fornecer uma formação socialmente útil." (FERREIRA, 2005, p. 191).

A leitura é tanto mais conservadora ao preconizar que o Brasil passaria pelas mesmas etapas das nações modernas, desconsiderando assim as suas próprias especificidades. A forma mais premente de tal conservadorismo repercutia os problemas do Brasil como oriundos de uma sociedade doente moralmente. Desta forma, evitava-se e escondia-se que o problema de outra ordem.

O texto está organizado em quatro tópicos: considerações gerais para a leitura de Primitivo Moacyr; Conjeturas sobre o lugar da instrução na condição republicana brasileira; O referencial de instrução republicana - observações de Primitivo Moacyr; A participação da República no fomento da instrução pública primária.

\section{Considerações gerais para a leitura de Primitivo Moacyr}

No conjunto de "Crônica Inactual”, Moacyr reporta-se com frequência ao pensador Bertrand Russel. (MOACYR, Chronica Inactual VI, 1929). Desta forma, podemos entender muitos de seus posicionamentos a partir do referido autor. Entre estes, a crítica de Moacyr à forma apaixonada e sem justificativas como alguns deputados tratavam da instrução (o uso 
de argumentação artificial do direito adquirido, com prevalência sobre os interesses da nação e da coletividade). Outro ponto é sua adesão à concepção de escola como espaço de formação das crianças e jovens para o uso de argumentos e evidências para pensar por si mesmas, condição necessária no combate a toda forma de dogmatismo e promoção da radicalidade da liberdade de pensamento.

Do ponto de vista pedagógico, a mais significativa influência é representada na crítica do filósofo às tendências psicologizantes do ensino, em especial as de John Dewey (1859 1952) e seu relativismo pedagógico, contribuindo para o enfraquecimento a condição objetiva do conhecimento. Uma última identificação de Primitivo Moacyr com Russel encontra-se na afirmação do valor do conhecimento em si mesmo, na condição de constitutivo do sujeito, ao subsidiar sua relação e condições de leitura do mundo, a percepção da realidade.

Nessa perspectiva, à semelhança de Bertrand, Moacyr defendeu a dependência da formação das novas gerações do seu contato com o saber acumulado na história dos homens, que considerou tributário do processo civilizatório, e, portanto, finalidade da educação. A função da educação seria superar a condição de serviçal de dogmas, convenções e ideias preconcebidas (mentalidade de rebanho). À escola incumbiu tornar as crianças e adolescentes livre nas dimensões intelectual e emocional. O que se consegue por direcionamento intencional, num claro rechaço dos ambientes de liberdade: a presença do adulto deve evitar que as relações entre as crianças e adolescentes se organizem pela lei do mais forte. Entretanto, alertava contra as relações sádicas no trabalho com o conhecimento. (RUSSELL, 1978).

Segundo Venâncio Filho a forma de manifestar-se de Primitivo "[...] aparece nos grifos expressivos [...]." (1943, p. 96). Estes, abundantes nas publicações "A Instrução e o Império" e "A Instrução e as Províncias", encontramos reduzidos nas publicações "A Instrução e a República", em especial e nas três últimas de 1942 e 1944. Segundo Barros (1936) o autor evitou deliberadamente o comentário, o debate. Ao comentarista do "Diário da Noite" pareceu até natural que o fizesse, visto que a tendência daquele momento era comparar a instrução do Império e República em uma discussão ociosa, em função da completa diferença entre os dois regimes e da complexidade dos anos republicanos. $\mathrm{O}$ articulista compreendeu que a questão não merecia atenção, por isso fora abandonada por Moacyr, que se ocupou de "[...] realizar um trabalho de pura e honesta documentação" (BARROS, 1936, p. 2).

Entretanto, a observação mais atenta das publicações indicam não tratar de forma única de expressão e posicionamento. Na retomada de projetos, ideias e fatos descreve-se um movimento que perpassa suas publicações no qual é possível identificar a importância atribuída a determinados problemas e dimensões do processo de construção do tema da instrução no Brasil. A estratégia de organizar uma escrita da história da educação a partir de textos de terceiros não impediu a manifestação de seu próprio discurso acerca da situação e dos desdobramentos da educação brasileira. $\mathrm{O}$ processo de investigação considerou a existência de posturas e ideários no autor, que permitem identificar análise própria do tema da instrução no imbricado processo de seu tempo, apesar da crítica historiográfica de que realizou uma escrita positivista da história na qual os fatos falam por si mesmos.

Desta forma, norteamo-nos pela identificação de que Moacyr enveredou-se por uma construção que demarca o conteúdo das discussões e proposições que amadureciam com o passar das décadas. A organização dos textos deu-se pela intenção de indicar um processo de reorganização das forças políticas, sociais e culturais em torno de um projeto nacional, 
por meio do qual se consolidaria o sentimento de pertencimento ao Brasil. Dito de outra forma, a escrita de Primitivo Moacyr revela um pesquisador de fatos e objetos nos quais se amontoavam conteúdos pelos quais nutria interesse. O seu esforço de preservação da memória da instrução nacional repercute função social e compromisso político assumido.

Naquele contexto, o descaso com a instrução pública é compreensível no interior de um projeto sociopolítico mais amplo, no qual desafios mais emergenciais se impuseram, como a priorização de questões de ordem estrutural na economia, na estrutura de Estado e na política, como aparecem nos relatórios oficiais. Desta forma, o leitor de Primitivo Moacyr deparar-se-á com recortes que indicam fatores do desinteresse do Estado: a carente estrutura financeira e o modelo de estabilidade política perpetuada no período, o imperativo de demandas de ordem estrutura na produção e comercialização da atividade econômica.

A retomada acalorada do papel da instrução popular nos meados dos anos 1910 devese à configuração de novas forças sociais e movimentos sociais, políticos e intelectuais que nos 1920 consolidaram a defesa da universalização, com exigência de maior presença da União no processo. A forma como Primitivo apresenta discursos/debates antagônicos indica a sua preocupação em representar a realidade complexa, contraditória e conflituosa, na qual o movimento da modernidade significou a formalização da crítica explícita ao predomínio do projeto das oligarquias tradicionais. (LEME, 1984).

A contribuição dos "profissionais da educação" e intelectuais, inseridos no processo que repensou a República, permitiu o debate da escolarização no âmbito da sociedade civil mais ampla, por meio das reformas estaduais, das conferências da educação, da reconfiguração da luta entre católicos e escolanovistas, bem como, o acirramento dos debates no Congresso Nacional. É o que demonstra a multiplicação de obras sobre o tema (biblioteca de Educação e Coleção Pedagógica; revistas, congressos, conferências da Associação Brasileira de Educação; inquérito Fernando de Azevedo em 1926).

Assim, o esforço intelectual em contribuir com a superação das limitações da gente brasileira num projeto de reinvenção da nação, elegeu escola como instrumento de formação para o progresso dentro da ordem. O que na prática significou evitar as revoluções e conturbações sociais e políticas. A mensagem regeneracional como força motriz de reação ao todo risco de ruptura na sociedade proliferou-se nos discursos dos intelectuais comprometidos com o tema da instrução. Segundo Monarcha

[...] evidencia a impossibilidade da sociedade burguesa refletir-se a si mesma, sob o risco de autodestruir-se. Para dissimular a divisão interna, criou-se identificações imaginárias e instâncias unificadoras como: a Lei, o Estado, o Direito, a Organização, a Família, a Ética do Trabalho, a Ciência, a Igualdade, a Liberdade e a Nação-Povo. (MONARCHA, 1989, p. 52 .

A publicação de Moacyr, fruto daquele contexto, demonstra o tratamento dado à instrução primária. O autor inseriu em sua organização da escrita da História da Educação a diversidade dos posicionamentos, nos quais diferentes atores veicularam perspectivas desde as últimas décadas do século XIX e primeiras décadas do século XX. De certa forma, o tema da escolarização era caro aos grupos hegemônicos presentes no interior das oligarquias (PERISSINOTTO, 1997), e estratégico para os trabalhadores "[...] particularmente destacados como os mais necessitados de instrução e de ações educativas. Assim, a demanda por educação formal e informal existente nos fabris foi também atendida pelos círculos libertários. (PERES, 2006, p.144).

O vínculo entre alfabetização e direito de voto limitava consideravelmente 
o colégio eleitoral, o que também poderia ser considerado como perda importante pela elite que disputava o eleitorado. A restrição de eleitores, provocada pelos altos índices de analfabetismo, acabou funcionando como uma forma de pressão da própria elite política em favor da alfabetização (BOMENY, p. 16 2003).

A importância da instrução para as classes inferiores e trabalhadores aparece nos recortes nos quais as proposições e medidas de acordos e subvenções entre a União e Estados sobre a instrução primária permaneciam "[...] sem andamento na Câmara", [...] "a época, aliás, era pouco propicia a tão nobres cogitações. No Congresso e na Administração os espíritos estavam todos trabalhados pelos espetáculos sanguinosos das oligarquias em luta e sucessões violentas de governos locais." (MOACYR, 1916, p.152). A respeito de como os intelectuais, que denomina de "comunidade de homens cultos", movimentavam-se nesse terreno, Monarcha (1989) afirmou:

Sabemos que a ideologia não apreende a sociedade em seus nexos internos, isto é, na sua divisão em classes sociais, polares e antagônicas, mas em sua exterioridade. Para a comunidade de homens cultos, a sociedade brasileira era atrasada devido à existência de força insubordinadas, conflitantes entre si, que impediam o surgimento da regularidade social - ordem - condição de desenvolvimento técnico e econômico - progresso. Essas forças sociais egoístas e competitivas ameaçam a autoconservação da sociedade burguesa. Para os homens cultos preocupados com a regeneração republicana, a eterna competição impedia a construção da consciência nacional, isto é, da universalidade imaginária e ilusão da unidade. (MONARCHA, 1989, P. 53).

O autor evidencia o conteúdo do pensamento de reconstrução dos anos 1910 -1930: a reorganização dentro da ordem, na qual a instrução pública é eleita como como elemento propulsor na modelação do povo. Assim, identificou o dado conservador da Escola Nova: a formação para a adaptação. A aproximação (acondicionamento) dos princípios daquela perspectiva pedagógica marcadamente de matriz privada (Europa e Estados Unidos) à defesa da escola pública é uma originalidade brasileira. Assim, o conceito de escola pública assumiu compromisso com o controle massas escolares emergentes, ao sabor do discurso da neutralidade científica e embalo do sonho de progresso. O problema situa-se no projeto de sociedade veiculado.

Os textos organizados por Primitivo Moacyr demonstram a valorização da sociedade racional e moderna. $O$ que o insere no grupo acima referenciado. Entretanto, não conseguimos identificar que participe da convicção dos muitos interlocutores ${ }^{6}$ a respeito do desinteresse do povo pela instrução. Postura que encontra-se nas expressões de Ministros, Presidentes de Províncias, Intelectuais, estudiosos da questão pedagógica, republicanos, recortadas por Primitivo Moacyr no interior dos debates oficiais. Em tempos republicanos o argumento encontrava-se inserido no bojo da luta pela reforma eleitoral, da superação progressiva e estratégica da servidão e da inserção do país no processo capitalista mundial, sob a condução das elites. Tal discursos discurso, reforçado na República, corroborou no adiamento da inserção do povo no direito de representação política. Moacyr indica nos processos do parlamento a inversão do desinteresse.

De forma geral, o objeto central de Primitivo Moacyr é a ação republicana, condicionada à pressão cada vez mais imperativa de urgência de um sistema nacional, cuja base fundamental deveria ser o ensino primário. As observações acima perpassam as publicações de Primitivo. 


\section{Conjeturas sobre o lugar da instrução na condição republicana brasileira.}

As publicações de Moacyr situam-se em contexto histórico, econômico, político e cultural de embates da constituição da escola pública brasileira e do papel que caberia ao Estado: os anos 1910 - 1930. Os livros do autor surgiram (1936 - 1944) quando a História da Educação tornava-se demanda nos cursos de formação de professores (Escola Normal) e no curso de bacharel em Pedagogia (SAVIANI, 2008), permitindo conjecturar que as publicações respondem a uma carência de conteúdo da História da Educação Brasileira nos manuais da disciplina. Em relação ao escrito de Pires de Almeida, a produção de Moacyr não apresenta função laudatória, seja ao Império e ou a República.

Naquela publicação de 1916, à primeira vista, parece realizar defesa do legislativo nacional acusado pela opinião pública de desapreço pelas causas do ensino público. O que existe é uma crítica em estilo cínico ao comportamento do legislativo sobre a instrução do povo. Na mesma descore-se os balizadores de seu posicionamento, que estão presentes em todas as suas publicações posteriores: a defesa de um programa de educação integral (primário, secundário, profissional e superior) e um esforço cultural que contribuísse para a configuração da nacionalidade (diligência com o ensino primário e secundário). Inserido num contexto de politização naturalista, de evolucionismo social e político, o autor evocar a contribuição da instrução no processo de explicitação da realidade.

A intensa proclamação da escola primária no Império e na República pautou-se por intensa atividade legislativa com poucas realizações conforme salientam boa parte dos pesquisadores da história da educação, que afiram ao final do século XIX e início do XX a centralidade da escolarização na "vida cultural brasileira." (CASTANHO, 2007, p. 43).

Saviani (2005) considera que o conteúdo dos debates configurados nos anos 18701880 se materializou na prática do poder público, assumindo o estado de São Paulo a referência de escola graduada. As acomodações de estabilidade do novo regime esvaziaram a condição universal estabelecida ao tema da instrução desde os anos finais do Império. Aos apagares das sessões legislativas, segundo Moacyr, destacou-se ${ }^{7}$ o constante adiamento e engavetamento das mais variadas proposições, viessem do Executivo ou do Legislativo, em especial as que tratavam da instrução elementar.

Tal discrepância deveu-se à configuração política, social e econômica dos primeiros tempos republicanos. A República das oligarquias locais, lugar efetivo da descentralização da escola elementar encontrava-se incapaz de atender à priorização da instrução. Foi no interior do tempo da Primeira República que se configuraram as condições para a necessidade da escolarização como condição da própria sustentação do modelo político, fundamentando-se no legado da finalidade moralizadora, cívica, civilizadora da educação (MOACYR, 1936; 1937; 1938; 1916; 1941; 1942c; 1944), com contribuição significativa da “comunidade dos homens cultos". (MONARCHA, 1989).

Nesta perspectiva, Nagle (1978) indicou a resistência responsável ao longo da Primeira República pelos padrões escolares do Império, expressos em diversidade de situações, em especial a ausência de uma ação política mais ampla, contraditando com o furor ideológico da democracia e da federação, que situava a instrução do povo como decisiva para a redenção do homem brasileiro, vez que a solução imigratória se demonstrou insuficiente e inviável ao longo da Primeira República. (CARVALHO, 2003). 
Por sua vez, Paschoal Leme (1984) entendeu que as alterações no cenário econômico do pós-guerra (1914-1918) reascenderam o tema e o movimento pela modernização política, econômica e cultural, acondicionada ao papel de centralidade que a instrução e a educação passaram a ocupar nos discursos e nas práticas.

Tais considerações confirma o fenômeno educacional como prática social inserida em uma totalidade concreta (SAVIANI, 2007), nos seus múltiplos fatores econômicos, políticos, culturais, científicos, classistas. Moacyr (1916) observou como as tendências oriundas desse processo debatiam-se no parlamento. A forma do confronto com que recortou as proposições, discursos e projetos no demorado processo dialético do parlamento, demonstra seu entendimento de que as ideias, instituições e debates são produzidos no interior de relações decorrentes na complexidade da realidade. Fato é que seus recortes, além de evidenciarem seus posicionamentos, comprovam a garantia do contraditório nos debates e confrontos que a história produziu no campo a que se reportou.

A historiografia da educação brasileira consolidou a retomada do tema da instrução primária como questão nacional na segunda metade do segundo decênio do século XIX (movimentos nacionalistas e cívicos), com sobre-excelência nos anos 1920-1930 por obra dos "Pioneiros da Educação" (ROCHA, 2004). A atuação do grupo consolidou-se em atuações de implementação de reformas pelos estados que se constituíram em ensaio da reposta pública, gratuita, laica e obrigatória. Moacyr comunga com tais perspectivas, embora não possamos identificá-lo com os pioneiros escolanovistas na sua totalidade.

No estabelecimento da República, estabelecimento condição moralizadora da anarquia intelectual e moral, tem a sua condição divisória, segundo Primitivo Moacyr, na convocação e realização da Conferência Interestadual de ensino primário para 1921, decorrente de convite aos estados por parte do Ministro do Interior, Alfredo Pinto aos Estados. O autor considerou que na inauguração do evento aconteceu um "discurso de estilo" por parte do Ministro, quando referiu-se na importância da redução dos analfabetos na constituição de classes laboriosas. $\mathrm{O}$ discurso em questão encerra o ensino primário na promoção do aumento do rendimento do trabalho, disputando espaço com segmentos de trabalhadores que incomodavam, como os anarquistas, comunistas e seus simpatizantes. (MOACYR, 1942c).

O resultado mais valorizado por Primitivo, nas conclusões daquela conferência, reporta-se à competência da União para atuar no ensino primário, por meio de ações de colaboração acordada com os estados, e outras possibilidades discutidas naquele encontro. O relevo que deu a tal competência (subvenção a escolas existentes e criação de escolas federais, com os estados elevando a $10 \%$ as despesas com as escolas existentes e definido os critérios da obrigatoriedade do ensino) indica a influência da história europeia da instituição da escola pública como obrigação do Estado Nacional. (MOACYR, 1942c).

Temos de considerar que alterações na ordem capitalista mundial nos primeiros trinta anos do século XX interferiram na economia e na política brasileira, como no caso dos encaminhamentos das políticas educacionais no sentido de promover acomodações no interior de um projeto autoritário redimensionado efetivamente nos anos 1930. O acordo político-social promoveu ideias pedagógicas e políticas que representaram a reconfiguração do próprio poder político em bases autoritárias. (ROCHA, 2004).

O ideário e a prática oligárquica dos primeiros tempos republicanos referentes à autonomia local resultou contraditório na medida em que solidificou a centralização às avessas, baseada no apoio que a política periférica dos estados dava ao governo central, na contrapartida aos interesses das oligarquias locais. Tal modelo, contribuiu para o ostracismo 
da escola pública primária em meio ao paradoxo da descentralização, que se apresentava como argumento democrático.

[...] embora a linha geral dos debates do final do império apontasse na direção da construção de um sistema nacional de ensino colocando-se a instrução pública, com destaque para as escolas primárias, sob a égide do governo central, o advento do governo republicano não corroborou essa expectativa. [...] o certo é que o novo regime não assumiu a instrução pública como uma questão de responsabilidade do governo central, o que foi legitimado pela primeira Constituição republicana. [...]. (SAVIANI, 2007, p.170).

Aquele serviu ao mando e controle oligárquico local, peça fundamental na "Política dos Governadores", que sustentou a base do poder autoritário da Primeira República. Primitivo Moacyr evidenciou, nos documentos e debates a que se reportou, a presença da justificativa de ausência de demanda social como fator fundamental do atraso da instrução primária. Há desconsideração das bases histórico-culturais da história nacional e local, o que tornava a responsabilização dos Estados e Municípios pela instrução pública do povo uma solução inadequada.

No caso da existência do desinteresse, os argumentos identificados pelo autor, negligenciam que o modo de produção, as relações e atividades de trabalho que perpassaram o Império e primeira República produziram o desinteresse do povo pela instrução. $O$ argumento não se sustenta como causa primordial sem a materialidade de uma sociedade de base econômica agrícola escravista cujo modus pensandi perpetuou-se na República.

De outro lado, a infraestrutura não constitui única explicação, dado que mesmo com alterações significativas no cenário econômico-social permanecia a lentidão na oferta da escola primária. Moacyr perguntava-se, referindo-se já aos últimos anos do período imperial e primeiros anos da República: por que estados (províncias) tão promissores no campo econômico repercutiam antigos problemas quanto à escolarização primária? (MOACYR, 1916; 1939a; 1938b; 1940).

Assim, esvaziou a tese amplamente difundida no Brasil das dificuldades explicadas só pela infraestrutura (economia) referenciada nas superestruturas (conjunto de ideias e instituições), mas configura-se em relações mais complexas que se entrelaçam nas duas dimensões. Isso não se coaduna com a responsabilização do povo na priorização da escolaridade, numa situação em que a função do Estado era "garantir o livre jogo das forças sociais em seu enfrentamento cotidiano no mercado e este, sim, seria capaz de organizar a sociedade: premiar os fortes e punir os fracos" (FARIA, 1996, p. 34).

Em meio às controvérsias, São Paulo ocupou a condição de modelo de escolarização, pela amplitude e pelo formato. A contribuição paulista redefiniu a teleologia (sentido e a natureza) da instrução pública brasileira, entremeando-se na constituição da nova moral e caráter nacional para a constituição do novo tempo. Numa dimensão higienista do corpo e do espírito, fundamentos e procedimentos legais e político-administrativos presentes no período imperial são reconfigurados na República.

No conjunto da obra de Primitivo Moacyr, identifica-se que o imbróglio da política de instrução popular republicana, conflito centralização/descentralização ${ }^{8}$, resultou da condição de uma sociedade de relação patrimonial que permitiu adiar, por décadas, o sonho de modernidade da instrução, na sua condição pública, livre, gratuita e obrigatória. São questões que perpassam a história da educação republicana até os dias atuais, conforme evidenciado na definição de tempos e projetos distintos da história da escola pública na 
República. (SAVIANI, 2005a; 2005b; 2006).

Assim, as publicações de Moacyr evidenciam tendências que se fazem presentes na contextura do entrecho, evidenciando fios que explicam suas perspectivas de olhar a história, bem como transparentam a função social e política da instrução da sociedade. As poucas palavras que usa em peça de promoção do empreendimento cultural "Coleção Brasiliana" explicitam a compreensão do autor da instrução: A Companhia Editora Nacional, por meio da "Brasiliana", prosseguia em sua corajosa iniciativa de "servir a nação", servindo à organização e orientação do público brasileiro (CORREIO PAULISTANO, 1937, p. 13).

\section{0 referencial da instrução republicana - observações de Primitivo Moacyr}

A dedicação de dois volumes à instrução em São Paulo enceta o mesmo projeto realizado com as províncias. Desconfia-se que o autor pretendia organizar publicações sobre outros estados. Não se trata só de assumir São Paulo como modelo da escola republicana tematizada nos grupos escolares. A idade avançada e a saúde não lhe permitiram tal empreendimento. Há notícias de que tenha organizado o volume da instrução em Minas Gerais.

De qualquer forma, a organização da história da instrução promovida por Moacyr acentua os ideais e os princípios de uma escola pública de matriz burguesa liberal. Nesta, o principal intuito era a inserção do "povo" no processo de formação do ideal de homem brasileiro, como acentuou na caracterização da organização escolar e sua articulação pedagógica. Moacyr identificou na ação paulista uma condição mais avançada para responder ao objetivo de formular o espírito público nos indivíduos.

Uma segunda identificação dá-se no fato da totalidade da obra de Moacyr demonstrar predileção pelo tema da instrução primária, mesmo quando o assunto central eram outros níveis de ensino. A preferência dá-se por considerar a condição estratégica da instrução elementar na constituição da nação e do progresso. Desta forma, nos limites das possibilidades da própria vida, valorizou na experiência paulista (século XIX) como tentativa de um sistema orgânico de ensino representado na organização administrativa e pedagógica composta de órgãos centrais e intermediários; na formulação de diretrizes e normas pedagógicas; na superação do modelo isolado de escola primária herdada do império. O autor entendia imprescindível a constituição de uma estrutura específica para a formação do homem nacional, agora urbano e com necessidade industriosa. (MOACYR, 1942a; 1942b).

A combinação de circunstâncias e de acontecimentos que consolidaram a oligarquia paulista na política nacional por meio da "Política dos Governadores" no governo Manoel Ferraz de Campos Salles ${ }^{9}$, na qual os pilares da moderna sociedade consolidavam-se nas soluções de infraestrutura de comunicação e transporte.

A opção por publicar a experiência de São Paulo demonstra que Moacyr compreendia os grandes desafios, problemas e limitações da instrução enfrentados naquela unidade administrativa, como questões que se apresentavam nas demais unidades da federação. Entre elas a carência de professores e sua inadequada formação; deficiência da inspeção; necessidade de prédios próprios; salários humilhantes e a cada vez mais imperativa contribuição da União; pobreza da população (acesso, vestimentas, necessidade de ajudar no trabalho). (MOACYR, 1916; 1936; 1937; 1938; 1939a; 1939b; 1940; 1941a; 1941b; 1942a;

Revista HISTEDBR On-line, Campinas, $n^{o}$ 61, p.30-50, mar2015 - ISSN: 1676-2584 
1942b; 1944).

Desta forma, a tese não se resume na intenção ou tendência modelar. $\mathrm{O}$ autor procura, no nascedouro da República, pelas circunstâncias promissoras do empreendimento da instrução pública. A questão fundamental que perpassa o relato historiográfico de Moacyr refere-se a como problemas tão comuns aos demais permaneciam em estados economicamente avançados, mesmo em São Paulo.

No processo da escola primária no Estado de São Paulo, o Decreto no 27, de 12 de março de 1890 (MOACYR, 1942a, p.69-74) estabeleceu a Escola Normal como suporte estratégico na promoção da instrução. A missão confiada por Estado Prudente José de Moraes e Barros ${ }^{10}$ a Caetano de Campos ${ }^{11}$ movia-se pelo conceito do educar como sendo um processo de orientação de mudanças. A primeira delas referia-se aos professores " [...] instruídos nos modernos processos pedagógicos e com cabedal cientifico adequado às necessidades da vida atual" (MOACYR, 1942b, p.70).

A própria forma de seleção e contração dos professores da Escola Normal ${ }^{12}$, prerrogativa de Caetano de Campos, subsidiada pelos critérios [maiores restrições na seleção dos alunos (portadores do domínio dos rudimentos das matérias basilares do ensino primário); proibição do aproveitamento de exames feitos em outros estabelecimentos; exigência de permissão governamental para exames vagos (comprovada proficiência, moralidade e destacado exercício da profissão); implantação das Escolas Anexas encantam Primitivo Moacyr. O que se evidencia por ocasião do relato do Regimento de 14 de junho de 1890 que atendendo aos dispositivos do decreto ${ }^{\circ} 27$ de reforma da Escola Normal (12 de março de 1890), recebeu de Moacyr o seguinte destaque: as lições "[...] mais empíricas do que teóricas e o professor se esforçará para transmitir a seus discípulos noções claras e exatas, provocando o desenvolvimento gradual de suas faculdades" (MOACYR, 1942b, p.73).

Moacyr assume que os ensino moderno precisava de novas formas e processos pedagógicos, daí sua admiração por Caetano de Campos ao compreendê-lo para além da função de burocrata. Nele colou o conceito moderno de ensino do "[...] acostumar o menino a refletir, dirigi-lo de modo a fazê-lo descobrir por seu próprio esforço as verdades que lhe são necessárias. O mestre é um guia. Educar vem de educere, conduzir. Os processos intuitivos são, pois, a base do ensino moderno" (MOACYR, 1942b, p.76). A simpatia de nosso autor por novos métodos que favorecessem o ensinar e o aprender marcam a escrita historiográfica, como se vê de sua atenção ao parecer Rui Barbosa. Assim, deu à Escola Normal a identificação de condição estratégica da instrução na discussão e ensino das possibilidades de processos educativos, que contribuíssem para o cultivo do espírito, da moral por meio do conhecimento.

Vê-se daqui quanto trabalho precisa o professor vencer para ficar à altura das necessidades do magistério. Modificar tudo o que se ensinava; tudo encaminhar nos diversos ramos de conhecimentos para explicá-los por novos processos; sobretudo fazer perder o hábito de decorar, o que só se obterá escrevendo novos compêndios, adicionar às matérias que outrora se ensinavam, muitas outras que completam a instrução indispensável que deve ter o professor, que foi, em poucas palavras, o espírito da reforma da Escola Normal. (MOACYR, 1942b, p.78).

O professor é definido em Primitivo Moacyr como um estudioso das maneiras de ensinar e aprender. A ele entendeu caber a promoção de situações que colocassem as crianças e jovens em contato com o conhecimento científico, e lhes incitassem ao desenvolvimento 
do gosto por novas descobertas, que lhes oportunizassem a construção da autonomia.

"Os republicanos mitificaram o poder da educação a tal ponto que depositaram nenê não apenas a esperança de consolidação do novo regime, mas a regeneração da Nação" (SOUZA, 1988, p. 15). A formação de professores prefigurada na Escola Normal de Caetano de Campos é identificada como eixo fundamental da instrução Republicana, segundo o recorte de Primitivo. No seu entendimento, sem ela, ficaria comprometida a universalização da instrução, substrato da democracia e sociedade progressista a ser estabelecida, por meio do cultivo do espírito, da moral e do conhecimento. Observamos a consolidação do caráter redentor da escola na esteira da instrução pública como produto da sociedade urbano industrial, o que a situa como resultado e promotora da democracia burguesa, em sua essência conflituosa.

[...] dantes pagava a Nação os professores dos príncipes sob pretexto de que estes careciam duma instrução fora do comum para saber dirigi-la. Hoje o príncipe é o povo, e urge que ele alcance o "self-government" pois só pela convicção cientifica pode ser levado, desde que não há que zelar o interesse de uma família privilegiada. A instrução do povo é, portanto, sua maior necessidade. Para o governo, educar o povo, é um dever e um interesse: dever, porque a gerência dos dinheiros públicos acarreta a obrigação de formar escolas; interesse porque só é independente quem tem o espírito culto, e a educação cria, avigora e mantem a posse da liberdade. (MOACYR, 1942b, p.87).

De forma ampla, não se trata de uma perspectiva economicista que reduza os embates enfrentados na constituição da instrução primária à estratégia de conformação da nação. Moacyr observou nas ações de Caetano de Campos a ampliação da responsabilização do governo conforme exigia a dinâmica do progresso, bem como a redefinição do conceito de escola como espaço fundamental da instrução pública do "grande proletariado" (MOACYR, 1942b, p.90). Ao estado imputava a prevalência da responsabilidade do Estado na superação da inferioridade cultural, por meio da promoção do acesso ao pensamento abstrato e da experimentação das ciências do mundo físico.

\section{A participação da República no fomento da instrução pública primária}

Moacyr foi influenciado pelo pensamento jurídico de Rudolf Von Jhering (18181892), e nas primeiras décadas do século XX, travou contato com as ideias de Bertrand Russel (1872-1970), dos quais concluímos ter assumido posicionamentos a respeito das questões educacionais. Dos dois autores, decorre a fundamentação da instrução como espaço de construção da autonomia dos indivíduos, no qual o professor e os conteúdos assumem uma centralidade numa atribuição peculiar da condição moralizadora, cívica e civilizadora da educação no interior do processo de formação da intelectualidade como condição da cidadania republicana. Alcançou-se como resultado a identificação de que há uma intenção e uma consistência em sua obra, qual seja, a defesa da federalização do ensino primário, como observamos nas publicações de 1916, 1942 e 1944.

O ordenamento do contexto pressionou por uma política mais ampla de desenvolvimento do sistema escolar na segunda década do século XX. Nos discursos (contestação e proposições de projetos e emendas) tornava-se imperativa a exigência de maior esforço de contribuição da União para com os estados. Ao longo de duas décadas, travaram-se argumentos a favor e contra a questão, como Moacyr reitera. As posturas 
políticas oficiais quando engendram os conteúdos escolares, apesar da peculiaridade escolar que as marca, "[...]são produtos e processos relacionados com as lutas e os embates da sociedade que os produziu e foi também produzida nessa e por essa escola. (PESSANHA; DANIEL; MENEGAZZO, 2004, p. 58). Questão que ainda de arrasta pelos tempos atuais, apesar dos enormes avanços.

A Reforma Benjamim Constant (Dec. 981, de 8 de novembro de 1890) definiu o compromisso da União com o ensino Primário e Secundário na Capital, na tradicional perspectiva de referência para os estados, numa forma que tentava conciliar estudos literários e científicos. O texto legal preconizava "[...] a instrução primária, livre, gratuita e leiga no Distrito Federal" (MOACYR, 1941, p.43). Isso no que se refere a oferta pública. De outro lado, permanecia a tendência da liberação da abertura de estabelecimentos de ensino por particulares.

O projeto respeitava a organização do Estado brasileiro em bases federativas, mantendo se uma certa tradição herdada do Império. A presença de conteúdos de bases científicas e menos literárias, pensadas para a performance do processo de modernização da economia e da sociedade brasileira, é uma influência positivista.

Os processos políticos que se seguiram à Proclamação da República submeteram a sociedade brasileira a um processo legislativo regulamentador das instituições ao regime federativo, permanecendo a sociedade e política ajustadas aos interesses das oligarquias regionais e municipais. A proposta de reorganização da instrução sob inspiração positivista (CERVI, 2005, p.52) conflitava com as perspectivas que exigiam uma maior centralização do processo. Referimo-nos ao projeto de sociedade que tornou-se hegemônico.

Entretanto, apesar das propostas da União reforçarem a tradição de distanciamento do governo central do ensino primário, Moacyr compreendeu que Benjamim se viu diante da necessidade de enfrentamento do analfabetismo (MOACYR 1941), inserido no movimento de defesa de ampliação da oferta da escola elementar. Entretanto, "[...] o entusiasmo pela educação nos primórdios da República teve pouco fôlego. O Ministério da Instrução Pública, Correios e Telégrafos durou três anos. À reforma Benjamin Constant, que não vingou, seguiram-se outras" (CERVI, 2005, p.52).

A organização da obra de Moacyr insiste na instrução primária, como já relatamos anteriormente. A concentração dos projetos e propostas oficiais das duas primeiras décadas do século XX no ensino secundário e superior não impediu que acentuasse os poucos momentos em que o tema da instrução elementar insistia em eclodir. Assim, a presença nos meandros dos debates parlamentares e das propostas do poder executivo nacional, explicitam um processo de alteração da condição de personagem ocasional, sempre na dependência das reformas dos outros dois segmentos, à condição imperativa no governo da República.

A título de referência, a situação ocorre quando o autor tratou das discussões e processos das reformas de 1911 (reforma Rivadávia Corrêa) e 1915 (reforma Carlos Maximiliano). Daquela discussão do ensino superior e secundário, Moacyr fez ver que o debate da instrução tangenciava o princípio da responsabilidade ou não do Estado para com a instrução nacional do povo. (MOACYR, 1942c). Referia-se à questão prioritária. Assim, revelou que a discussão das reformas e projetos parlamentares dá-se inserido em contexto de tensão social e política, como é próprio das sociedades, modernas quando a demanda da instrução primária se apresentava como obrigação do Estado nacional.

Desde os 1910 as proposições articularam-se num e a partir de contexto de pressão pela ampliação da instrução popular com maior participação da União junto aos estados. O 
que expressou-se no Brasil em duas tendências. Uma que propugnava a alfabetização como solução. A outra, mas abrangente, defendia a proposta de educação geral centrada na formação moral e cívica, em um claro compromisso com a precaução dos riscos de uma instrução descontrolada (CARVALHO, 2003).

As condições sócio-políticas do contexto sugestionaram soluções autoritárias de ensino. A meta era a acomodação das forças conflitantes na sociedade, que se consolidaram na história brasileira a partir dos anos 1910. A reforma Rocha Vaz em meados dos 1920 resultou desse processo. Em "O Ensino Público no Congresso Nacional - Breve Notícia" (1916) Moacyr inicia o texto com a defesa sarcástica do Congresso Nacional, ingenuamente identificada pelo leitor desatento ao conjunto da obra como elogio.

A opinião pública é talvez injusta quando acusa o Congresso de desapreço às cousas do ensino público. A sua operosidade, no caso, tem sido copiosa. Em vinte e quatro anos de regime republicano cerca de oitenta projetos de parte as anuais e quase clandestinas disposições orçamentárias - foram oferecidos ao estudo da legislatura. Tão boa vontade só encontra parelha nas mercês e favores ás classes armada e ao funcionalismo civil [...] (MOACYR, 1916, p.5).

A essência do parágrafo apresenta uma linha de pensamento que encontramos em toda a publicação de Moacyr, em especial nos volumes "A Instrução e a República": o autor denuncia a desvinculação da instrução de um projeto mais amplo e ambicioso de sociedade, diga-se, de nacionalidade. Uma das características de Moacyr é, ao apresentar os projetos, considerar toda o processo de tensionamento a que foram submetidos e do qual resultavam. Daí sua preocupação em fazer os percursos dos motivos que geraram cada proposta, da configuração e da submissão ao processo parlamentar, onde enfrentava o embate com as forças ali representadas. O relato do processo de discussão do Projeto Tavares de Lyra, de 1907, vem acompanhado da identificação de Moacyr: "pela primeira vez, no regime republicano, a Legislatura recebe um documento deste gênero com ideias definidas sobre a instrução integral, desde a primária até o curso superior." (MOACYR, 1916, p.109).

Deste ponto em diante, observamos que Moacyr insiste em recortes que evidenciam a função supletória da União, na relação com os estados, na forma de acordos e estabelecimentos de princípios gerais. Na proposta de Lyra, destacou que critérios fundamentais da subvenção se impunham-se aos demais, a saber, a "idoneidade técnica e moral do professor", ensino laico e gratuito, a permanência das "[...] escolas sob a fiscalização da União enquanto subvencionadas", e a obrigação do Estado manter a escola ao fim da subvenção. (MOACYR, 1916, p.110). A intervenção direta da União na instrução primária defendida por Lyra recebeu críticas severas no parlamento. O Ministro foi acusado de carecer de ideias originais. A respeito desse fato, temos umas daquelas poucas ocasiões em que o texto nos permite saber que é o próprio Primitivo Moacyr a expressar-se. No caso ressaltou o mérito da proposição e sua coragem de inovação.

[...] em vez de representar o pensamento exclusivo de um dos membros da Comissão ou programa pessoal do Ministro, resulta o trabalho em debate de uma harmonia de vistas entre homens que desejam acertar. [...] de fato, ele tem uma ideia nova, de alta importância, qual seja a intervenção direta do Governo da União no ensino primário. (MOACYR, 1916, p.123).

O projeto Tavares de Lyra foi mutilado no Senado. Ao referir-se a tal procedimento, Moacyr denunciou a influência positivista. No seu entendimento, na primeira década republicana, tal perspectiva contribuiu para a construção da anarquia do ensino, ao posicionar-se contra qualquer tipo de sistematização e ordenamento lógico e pedagógico,

Revista HISTEDBR On-line, Campinas, $n^{\circ}$ 61, p.30-50, mar2015 - ISSN: 1676-2584 43 
contra autoridade aglutinadora dos interesses gerais da instrução; e essencialmente, ao impedir a intervenção colaborativa. (MOACYR, 1916). As questões fundamentais da organização da instrução foram relegadas a interesses partidários e corporações; compreensão equivocada do princípio de autonomia didática e administrativa.

Na sequência do texto Primitivo Moacyr demonstrou a ausência de razão no discurso do deputado Manoel Bonfim que afirmava ser o projeto de Lyra a "[...] primeira vez que no Brasil se cuida dessa intervenção" (MOACYR, 1916, p.123). O autor retomou os que décadas antes haviam defendido o instituto da intervenção: Passos de Miranda em 1904 autorizava a União a entendimento com os governos locais para organização e sistematização do ensino primário e técnico profissional elementar (MOACYR, 1916, p.145); Barbosa Lima em 1906; José Bonifácio no mesmo ano. Deste deputado Moacyr registou a afirmativa da existência de consenso legislativo em 1911 a respeito da presença do Governo na difusão do ensino primário nos estados. (MOACYR, 1916).

Apesar da identificação do movimento favorável à intervenção, a Moacyr era incomodava que a Câmara não acolhesse o propósito de abertura de crédito para viabilizar as propostas, e que, dois anos mais tarde, autorizasse a reforma de Rivadávia Corrêa do ensino superior, que atendia a interesses particulares e das classes altas.

Os argumentos do deputado Manoel Bonfim publicados na "Revista Pedagógica" em 1897, retomados no discurso proferido na Câmara por ocasião da discussão do projeto Lyra confirmavam "[...] todos os governos [...] intervêm na organização moral e política da escola primária [...] o que não conheço é país onde o governo central se despreocupe [...] ignorando, por inteiro, tudo o que a isto se refere." (MOACYR, 1916, p.155).

O movimento de parte dos parlamentares em defesa da contribuição da União permaneceu. Augusto Lima em 1912. Félix Pacheco (Comissão de Finanças) em 1913, por entender ser de interesse do processo de civilização do Brasil, do regime republicano e de todos os estados, postulou o ensino primário como obrigação também do Estado Nacional, na consolidação da democracia e do engrandecimento do país, por meio do exercício, cada vez mais universal, do voto. (MOACYR, 1916). Novidade numa comissão considerada por Moacyr como espaço de desilusão das iniciativas em prol da instrução pública.

Outro projeto colocado evidenciado por Moacyr é de autoria o deputado Miguel Calmon. A formação dos professores pela Escola Normal é a condição básica apresentada pelo parlamentar para o empreendimento da instrução popular. É uma retomada da propositura de Manoel Bonfim. O desafio que Calmon colou-se para a contribuição da União da instrução elementar, segundo Moacyr, deu-se em estabelecer soluções que desviassem do impedimento constitucional. A normatização das Escolas Normais Superiores ${ }^{13}$, para a formação de professores para as Escolas Normais primárias dos estados, seria uma possibilidade. Os críticos, por sua vez, alegavam a permanência da inviabilidade constitucional. Eram motivados pelo vínculo teórico político entre Escola Normal Superior e ensino primário. Os defensores da proposta argumentavam a função política da que impunha à União a competência para com o ensino primário: zelo da soberania nacional, cuidar da "cultura das massas".

Apesar de tais argumentos, "devemos mais uma vez dizer que a Comissão de Instrução da Câmara quedou-se silenciosa" (MOACYR, 1942c, p.229). A essa altura, enquanto, no encaminhamento parlamentar, as discussões da estrutura da educação pública esbarravam na inconstitucionalidade das ações interventivas, o paradoxo teórico da resistência foi tipificado como incongruente por Raimundo Braga, relator do projeto Lebon Regis ${ }^{14}$. Afirmou não se tratar mais de limitações e dificuldades da exegese do texto 
constitucional. A contradição estaria em outro campo.

E parece mesmo singular e extravagante que haja um povo vivendo, desenvolvendo-se e progredindo, sob uma Constituição liberal que permite a governos estrangeiros a criação e manutenção de escolas estrangeiras em seu território, e que, no entanto, proíbe ao Governo Nacional que o faça. É singularidade que talvez possam explicar os doutores da materialidade constitucional, os versados em letras constitucionais, mas com a qual o meu espirito tosco e achavascado não atina (MOACYR, 1942c, p.315).

As evidências indicam que o gargalho não se reduzia a condições de ordem econômica. Havia que se considerar o descompasso do governo central e seus aliados quanto ao funcionamento da República Federativa. O princípio republicano federativo apresentava em condução equivocada na realidade específica brasileira. Segundo o deputado José Augusto confirmava-se a ausência de "proibição expressa ou implícita" no texto constitucional (MOACYR, 1942c, p.316) do compromisso da República com a instrução primária.

Esqueceram que a República é, sobretudo, um regime de cooperação em que, para as obras de nosso engrandecimento, não se compreendem exclusividades. Desde que se trata de altos interesses da nacionalidade, arriscados a grande dano, a Federação está obrigada a completar, e até substituir, a livre atividade dos Estados (MOACYR, 1942c, p.315).

$\mathrm{O}$ assunto da responsabilidade nacional pela instrução seguiu polêmico, mesmo sob novos enfoques: permanecia a discordância oriunda da resistência das oligarquias quanto ao processo de recuperação do homem brasileiro na configuração histórico-cultural. Moacyr reportou-se a discussão na reforma Rocha $\mathrm{Vaz}^{15}$ : vivia-se um novo contexto que possibilitava definir a instrução primária como prioridade do Estado, numa inversão de gastos para o segmento do ensino primário. "Penso, porém, que nesta matéria, ainda apelando para as economias em outros serviços, todo sacrifício atual deve ser aplaudido e será de larga compensação em futuro próximo (MOACYR, 1942c, p.191)." Neste sentido, atuou-se na defesa de organização eficiente e de maior harmonia da liderança da União na unificação e uniformização do ensino primário. (MOACYR, 1942c).

Em sua obra não se encontra um trabalho sistematizado sobre a condição republicana da escola, mas identifica-se ao longo dos textos a defesa de alguns ideais que expressam a condição pública da instrução. Estamos nos referindo à perspectiva liberal da instrução: educação para a cidadania, tradição humanista, e a diversidade da demanda por "intensa formação profissional” decorrente da Revolução Industrial. (PAIM, 2007, p.2015).

Nas entrelinhas de sua organização da história da instrução, Primitivo Moacyr imprimiu sua marca: a preferência pela instrução popular (primária) sob responsabilidade da União, condição que a livraria da tutela e controle das oligarquias regionais e locais. $\mathrm{O}$ seu entendimento da complexidade da realidade evidencia-se no colocar-se de debates das mais contraditórias perspectivas desde o tempo da Monarquia ao primeiro período republicano. Não se trata de leitura única, uma que coloca o leitor em contato com proposituras diferenciadas e contrapostas. Além da escrita da história da instrução, na perspectiva do diagnóstico da sua situação na República, o autor esteve preocupado com uma proposta de âmbito nacional. 


\section{CONSIDERAÇÕES FINAIS}

A contemporaneidade e adesão à causa republicana não se apresenta em Primitivo Moacyr solidária à negação do passado e sua responsabilização pela situação do presente, conforme fora comum nos intelectuais e políticos republicanos de seu tempo. Do mesmo modo, não esteve interessado em que promover uma leitura positiva do Império e/ou República no trato da questão educacional. Não se trata de texto laudatório, mesmo quando deu destaque a determinados nomes e proposições, embora na sua escrita da história estejam presentes características de uma forma positivista de fazer história. De outro lado, a centralidade da instrução como mecanismo de construção do reordenamento do Brasil o insere a perspectiva positivista.

$\mathrm{O}$ autor procurou nos embates educacionais que se desenrolaram no Império e, de forma especial, a partir dos anos 1870, as raízes para pensar a escola primária. O conjunto da publicação no contexto das décadas de 1930-1940, precedida pela "Instrução pública no Congresso Nacional”, de 1916, elegeu como suportes os relatórios das autoridades da instrução na República, a legislação e os documentos do parlamento.

A contribuição do autor revela que os avanços da discussão teórica e da ação política têm origens no movimento de modernização que se iniciara no segundo Império. A experiência mais emblemática que apresenta são os grupos escolares, num contexto que delegou as primeiras iniciativas republicanas de racionalização e universalização do acesso à escola primária ao protagonismo dos estados.

$\mathrm{Na}$ sua leitura, os impedimentos e entraves que promoveram o adiamento da instrução elementar não foram unicamente de ordem econômica, como expresso em várias oportunidades, ao indagar os porquês províncias (na Monarquia) e estados (na República) tão promissores não conseguiam avançar na oferta daquele seguimento da instrução que considerava estrutural e definidor da própria condição republicana.

Outro posicionamento muito comum, em especial nos nomes relacionados ao movimento da republicanização, não tem respaldo nos posicionamentos de Primitivo Moacyr: o desinteresse do povo pela escolarização como um agravante. Embora não fique evidente como se posiciona, nas vezes em que tal argumento aparece nos documentos, não receberam de Moacyr o acento dado a outros temas.

Ao valorar a solução republicana paulista para a escola primária (com os objetivos capitaneados pela ideia da formação do novo homem nacional, no contexto das novas exigências do trabalho assalariado e da emergência de um novo pacto de estabilidade social na instauração da nova forma de poder), consolidou o papel do estado educador na efetivação de uma república solidificada no cultivo do espírito ancorado em bases morais e conhecimento científico, prefigurada no método intuitivo.

Os recortes de Moacyr indicam a instrução primária como central nos debates ao longo a partir da segunda década do século XX no que se refere à exigência paulatina da responsabilização do governo central. Questão para a qual buscou antecedentes nos reclamos das províncias ao longo do período imperial. A inserção de debates controversos permite afirmar a verificação de que o processo do debate da instrução respondeu à dinâmica sóciopolítica de cada período, na esteira das efervescências e contradições da sociedade, que se manifestavam na legislação e no parlamento.

O autor concorda que ao Estado republicano faltou um projeto de instrução pública

Revista HISTEDBR On-line, Campinas, $n^{o}$ 61, p.30-50, mar2015 - ISSN: 1676-2584 
mais amplo e ambicioso de nacionalidade. Nas críticas dos parlamentares ao projeto do ministro Tavares de Lyra, entre outros, identificou a ação supletória da União como ensaio do comprometimento da União na sua condição republicana. Assim, a institucionalização da escola pública, um dos critérios definidores da República para Primitivo Moacyr, encontrase no centro do debate sobre a organização e institucionalização estatal da escola primária.

\section{REFERÊNCIAS}

BARROS, Jaymne de. Espelho dos livros. Diário da Noite. Rio de Janeiro, p. 2-2. 2 nov. 1936.

BITTENCOURT, Circe Maria Fernandes. Pátria, civilização e trabalho: o ensino de história nas escolas paulistas (1917-1939). São Paulo: Loyola, 1990.

BOMENY, H. Os intelectuais da educação. Rio de Janeiro: Jorge Zahar, 2003.

CARVALHO, Marta Maria Chagas de. A escola e a república e outros ensaios. Bragança Paulista: EDUSF, 2003.

CASTANHA, André Paulo. O uso da legislação educacional como fonte: orientações a partir do marxismo. Revista HISTEDBR On-line, Campinas, número especial, p. 309331, abr2011 - ISSN: 1676-2584.

CASTANHO, Sérgio. Institucionalização das instituições escolares: final do Império e Primeira República no Brasil. In NASCIMENTO, Maria Isabel Moura; SANDANO, Wilson, LOMBARDI, José Claudinei, SAVIANI, Dermeval(orgs.). Instituições escolares no Brasil: conceito e reconstrução histórica. Campinas, SP: Autores Associados, 2007.

CERVI, Réjane de Medeiros. Padrão estrutural do sistema de ensino no Brasil. Curitiba: Ibpex, 2005.

CORREIO PAULISTANO. A coleção 'Brasiliana' comemorando o seu $100^{\circ}$ volume! Correio Paulistano. São Paulo, p. 12-13. 25 nov. 1937.

FARIA, F.A. Arquivos de sombras: a privatização do Estado brasileiro da Primeira República. Rio de Janeiro: Sette Letras, 1996.

FERREIRA, António Gomes. A difusão da escola e afirmações da sociedade burguesa. Revista Brasileira de História da Educação, n. 9, jan/jun. 2005. pp 177 - 198.

LEME, Paschoal. O manifesto dos pioneiros da educação e suas repercussões na realidade educacional brasileira. RBEP, Brasília, v. 86, n. 212, p.163-178, jan. /abr. 2005, com publicação original na RBEP v. 65, n. 150, p.255-272, maio/ago. 1984.

PESSANHA, Eurize Caldas; DANIEL, Maria Emília Borges; MANEGAZZO, Maria Adélia. Da história das disciplinas escolares à história da cultura escolar: uma trajetória de pesquisa. Revista Brasileira de Educação, Rio de Janeiro, n. 27, p. 57-69, 2004. Disponível em: <http://www.scielo.br/pdf/rbedu/n27/n27a04.pdf.> Acesso em: 24 maio, 2015.

MOACYR, Primitivo. O ensino público no Congresso Nacional, breve notícia. Rio de Janeiro: Typ. do Jornal do Commercio, 1916.

A instrução pública e a República(1917 - 1928). Chronica inactual I. Jornal do

Comercio. Rio de Janeiro, 1920

A instrução pública e a República (1917 - 1928). Chronica inactual VI. Jornal do

Revista HISTEDBR On-line, Campinas, $n^{o}$ 61, p.30-50, mar2015 - ISSN: 1676-2584 
Comercio. Rio de Janeiro, 1929.

A instrução e o Império (subsídios para a história da educação no Brasil) 18231853. v. 1. São Paulo: Nacional, 1936.

A instrução e o Império (subsídios para a história da educação no Brasil) 18501887. v. 2. Reformas do Ensino. São Paulo: Nacional, 1937. (Série 5. Brasiliana, v. 87).

A instrução e o Império (subsídios para a história da educação no Brasil) 18541887. v. 3. São Paulo: Nacional, 1938.

A instrução e as províncias (subsídios para a história da educação no Brasil) 1835-1889. v. 3. (Do Amazonas às Alagoas). São Paulo: Nacional, 1939a.

A instrução e as províncias (subsídios para a história da educação no Brasil) 1835-1889. v. 1. (Sergipe, Bahia, Rio de Janeiro, São Paulo e Mato Grosso). São Paulo: Nacional, 1939b.

A instrução e as províncias (subsídios para a história da educação no Brasil) 1835-1889. v. 2. (Espírito Santo, Minas Gerais, Paraná, Santa Catarina, Rio Grande do Sul e Goiaz). São Paulo: Nacional, 1940.

. A instrução e a República. .v. 1. Reforma Benjamim Constant (1890-1892). Rio de Janeiro: Imprensa Nacional, 1941a.

A instrução pública no Estado de São Paulo. Primeira década republicana 18901893. v. 1. São Paulo: Nacional, 1942a.

A instrução pública no Estado de São Paulo. Primeira década republicana 18901893. v. 2. São Paulo: Nacional, 1942 b.

A instrução e a República. v. 4. Reformas Rivadávia e C. Maximiliano. Rio de Janeiro: Imprensa Nacional, 1942c.

A instrução e a República. v. 5. Reforma João Luiz Alves - Rocha Vaz (19251930). Rio de Janeiro: Imprensa Nacional, 1944.

NAGLE, Jorge. A educação na Primeira República. In: FAUSTO, Boris (Org.). História geral da civilização brasileira. O Brasil Republicano e instituições (1889-1930). v. 2. t. III. São Paulo: Difel, 1978. p.261-291.

MONARCHA, Carlos. A reinvenção da cidade e da multidão: dimensões da modernidade brasileira: a Escola Nova. São Paulo: Crotez/:autores Associados, 1989.

PAIM, Antonio. O liberalismo contemporâneo. $3^{\text {a }}$ ed. Londrina: Humanidades, 2007.

PERES, Fernando Antônio. Estratégias de aproximação, sociedades de idéias e educação anarquista em São Paulo na Primeira República. Revista brasileira de história da educação, n. 11, jan./jun. 2006.

PERISSINOTTO, Renato M. Classes dominantes, Estado e os conflitos políticos na Primeira República em São Paulo: sugestões para pensar a década de 1920. In CARVALHO DE LORENZO; PERES, Wilma da Costa (org.) A década de 1920 e as origens do Brasil Moderno. São Paulo: Fundação Editora da UNESP, 1997,pp. 37 - 69.

ROCHA, Marlos Bessa Mendes da. Matrizes da modernidade republicana: cultura política e pensamento educacional no Brasil. Campinas, SP: Autores Associados; Brasília, DF: Plano, 2004. 
SAVIANI, Dermeval. História da história da educação no Brasil: um balanço prévio e necessário. Ecos. Revista Científica. São Paulo.. v. 10. N. especial. P. 147 - 167. 2008. 2007.

História das Idéias Pedagógicas no Brasil. Campinas, SP: Autores Associados,

Estágio atual e uma nova perspectiva para a História da Educação. In:

SCHELBAUER, Analete Regina; LOMBARDI, José Claudinei; MACHADO, Maria

Cristina Gomes (Orgs.). Educação em debate: perspectivas, abordagens e

historiografia.Campinas, SP: Autores Associados, 2006. p.9-21.

A política educacional no Brasil. In: STEPHANOU, Maria; BASTOS, Maria Helena Câmara (Orgs.). Histórias e memórias da educação no Brasil. v. III. Petrópolis, RJ: Vozes, 2005a. p.29-38.

História da escola pública no Brasil. Questões para pesquisa. In: LOMBARDI, José Claudinei; SAVIANI, Dermeval; NASCIMENTO, Maria Isabel Moura (Orgs.). A escola pública no Brasil: história e historiografia. Campinas, SP: Autores Associados, 2005b. p.1-29.

SOUZA, Rosa Fátima. Templos de Civilização: a implantação da escola primária Graduada no Estado de São Paulo (1890-1910), São Paulo, Unesp 1998.

STAMATTO, Maria Inês Sucupira. L'ecole primaire publique au Brasil de l'independance a la republique: 1822-1889. Thése pour le Doctorat - Université de La Sorbonne Nóuvelle, Paris, 1992.

TANURI, Leonor Maria. Historiografia da educação brasileira: contribuição para seu estudo na década anterior à instalação dos cursos de pós graduação. Mesa Redonda sobre História da Educação, 20 de outubro de 1997, no I congresso de Ciências da Educação, pela FCL/Araraquara e FEUSP. Araraquara. 140 - 153.

\footnotetext{
1 Universidade Estadual do Norte do Paraná - UENP / Email: luizantonio@ @enp.edu.br

2 Universidade Estadual de Maringá - UEM / Email: mcgm.uem@gmail.com

3 A revisão bibliográfica confirma a condição de referência clássica da obra de Moacyr enquanto contribuição para a historiografia da educação brasileira (STAMATTO, 1992). Trata-se de obra constantemente referenciada por autores que tratam de diversos objetos e variadas temáticas no contexto da referida produção historiográfica. Entretanto, não se confirma a condição de obra pesquisada. O que se podem identificar foram incursões em Moacyr, por conta de problemas e temas, motivados por diversos objetos da pesquisa em histórica da educação.

4 Os volumes que compõe a coleção "A Instrução e a República" forma publicados na forma de artigos no Jornal do Commercio, nos últimos anos da década de 1920 e primeiros anos dos anos 1930. Receberam o título sugestivo de "Crônica Inactual", enumeradas em romanos conforme a sequência das mesmas.

5 A relação entre Moacyr e arquivos construiu-se em longa data, desde as suas atividades na Câmara Federal, na organização dos "Documentos Parlamentares", e na própria busca de subsídios para ancorar as proposituras dos parlamentares. Seus estudos no campo da história da instrução foram acentuados a partir do primeiro quinquênio dos anos 1930, quando dedicou-se às pesquisas que resultaram no que ele denominava "activa selvaggia". O termo refere-se à atividade difícil em terreno desconhecido e, por vezes, perigoso, como era o parlamento e os interesses que se confabulavam.
} 
6 Definimos, como interlocutores de Moacyr, os Ministros, Presidentes de Províncias, Intelectuais, Estudiosos da questão pedagógica, entre outros, que fazem parte dos recortes de suas obras, e que, desta forma, permitem perscrutar as entranhas do processo da escola no Brasil, no interior dos debates oficiais.

7 O autor foi relator dos discursos parlamentares para a instrução na Câmara dos Deputados. Em 20/05/1895, foi admitido como Redator de Debates da Câmara dos Deputados; em 04/01/1910, foi designado Redator dos Documentos Parlamentares; em 27/11/1916, foi nomeado Chefe da Redação dos Debates, continuando, porém, incumbido dos Documentos Parlamentares, e em 07/07/1926, foi nomeado Redator dos Documentos Parlamentares.

8 Do ponto de vista da filosofia política, a descentralização representava um princípio liberal, enquanto que a centralização repercutia uma forma de incorporação do ideário positivista no Brasil. As repercussões destas duas perspectivas marcaram o debate da instrução no Império e, em parte, da Primeira República. Atingia-se a forma de indefinição do compromisso do Estado com a instrução popular em todo o país no aspecto legal e/ou financeiro, bem como a permissão, ou não, da iniciativa privada.

9 Advogado, nascido na cidade de Campinas, estado de São Paulo, em 13 de fevereiro de 1841. Foi deputado provinciano pelo Partido Liberal de São Paulo (1868-1869). Republicano histórico e portador de diversos mandatos em diversas instâncias da organização política, colaborador do Correio Paulistano, presidente do estado de São Paulo (1896-1897), assumiu Presidência da República, por eleição direta, em 15 de novembro de 1898, ministro plenipotenciário do Brasil na Argentina (1912). Faleceu na cidade de Santos, estado de São $\begin{array}{lllllll}\text { Paulo, em } & 28 & \text { de } & \text { junho } & \text { de } & 1913 . & \text { Disponível }\end{array}$ http://www4.planalto.gov.br/informacoespresidenciais/campos-salles. Acesso: 22 maio 2009.

10 Advogado, nascido na cidade de Itu, estado de São Paulo, em 4 de outubro de 1841. Formou-se bacharel pela Faculdade de Direito de São Paulo (1863). Por meio de eleição direta, passou a exercer a presidência da República em 15 de novembro de 1894. Chefia o Partido Republicano Dissidente de São Paulo (1901). Faleceu na cidade de Piracicaba, estado de São Paulo, em 13 de dezembro de 1902. Disponível em http://www4.planalto.gov.br/informacoespresidenciais/prudente-de-moraes. Acesso: 22 de maio de 2009.

11 Médico e educador, nasceu em 17 de maio de 1844, na cidade de São João da Barra, Estado do Rio de Janeiro. De família pobre, formou-se pela Escola de Medicina da antiga Corte, em 1867, participando como cirurgião da armada na Guerra do Paraguai. Em 1870, transferiu-se para São Paulo. Rangel Pestana, reconhecendo as altas qualidades de Caetano de Campos como educador, sugeriu a Prudente de Moraes, então presidente do Estado de São Paulo, sua nomeação para o cargo de diretor da Escola Normal, função que exerceu entre 1889 e 1891.

12 "[...] as aulas serão regidas por professores e professoras nacionais e estrangeiros, contratados mediante proposta do diretor da escola" (MOACYR, 1942b, p.70).

13 Escola que deveria, sobretudo, ocupar-se de pesquisar a infância brasileira em suas condições físicas e intelectuais, bem como oferecer oficinas de ensino. Para valorizar o curso, vinculou o acesso ao magistério público por meio de exames, para os que concluíssem seus estudos em Escola Normal.

14 Leblon Régis preconizava subvenção de 15 anos às escolas situadas nos núcleos estrangeiros de Santa Catarina.

15 A reforma João Luiz Alves também ficou conhecida por Rocha Vaz porque esse professor da Faculdade de Medicina foi o principal membro que elaborou o anteprojeto do decreto federal e dirigiu a execução da reforma (BITTENCOURT, 1990, p.25).

Recebido: $\quad$ março-15 abrovado: $\quad$ abril-15 